\title{
Is Obesity a Healthy Active Response to an Expected Future Lack of Energy rather than a Passive Storage of Surplus Energy?
}

\author{
Thorkild I.A. Sørensen \\ The Novo Nordisk Foundation Center for Basic Metabolic Research, University of \\ Copenhagen, and Institute of Preventive Medicine, Copenhagen University Hospitals, \\ Copenhagen, Denmark
}

The thermodynamic laws provide an exact quantitative description of obesity as a reflection of a cumulative surplus of energy intake relative to energy expenditure [1]. The prevailing interpretation of this physical truth is that the process of accumulation of fat is a passive storage of the surplus of energy caused by an energy intake that exceeds the expenditure $[2,3]$. This is a core assumption in the conventional concept of the obesogenic environment as being responsible for the obesity epidemic; the increasing exposure to energydense, palatable and cheap foods and drinks together with a variety of practical tools minimising demands of physical activity is assumed to make individuals gain weight, and most so those who suffer from genetically or environmentally programmed susceptibility $[3,4]$. Although experimental manipulation can enforce a positive and negative energy balance and, not surprisingly, can induce the predicted change in energy stores, including fat stores [2], naïve extrapolation of this evidence to the understanding of the causes of obesity may turn out to be a serious mistake [3]. This may be the reason why we generally have failed in both preventing and treating obesity effectively.

There are several reasons why the naïve interpretation of the cumulative positive energy balance is inadequate in the understanding of the development of obesity [2]. The quantity of fat accumulated per day is on average so small that measurement of it is beyond any available technique. Measurement while the accumulation is on-going would, had it been possible, just confirm the physical truth, from which we learn nothing new. A distinction between increase in intake and/or decline in expenditure as the initiating process would in theory be possible; however, in practice it would be impossible, also because of uncertainty about the timing of the initiation. Accumulation of fat could easily take place without an 
increased energy intake by a corresponding reduction in energy expenditure elsewhere in the body, and, as recently demonstrated in animal experiments, this may occur even under moderately reduced energy supplies [5]. While obesity develops, the energy expenditure tends to increase both because the basal metabolic rate increases alongside with the increases in metabolically active lean body mass and because any movement of the heavier body requires more energy $[1,2]$. Although development of obesity usually is associated with less physical activity, likely due to the greater difficulty and discomfort, the total energy expenditure increases, which leads to a greater need for energy, which the obese individual as anyone else will try to satisfy. Thus, the fairly easily observable reduced physical activity and increased food intake are consequences of obesity, and as well-established common knowledge it is unfortunately mistakenly interpreted as the 'obvious' cause of obesity.

The experimentally induced positive energy balance reflected in increase in fat stores does not match the obesity phenotype in several ways. In particular, the body weight gained during overfeeding experiments is easily lost again and kept off after the experiment [2], in contrast to the weight gained during obesity development; weight loss in obese individuals is a struggle and is almost inevitably followed by weight regain sooner or later [6]. One could argue that it is just a question of having the overfeeding going on long enough to allow various adaptations to create the obesity phenotype, but this has not been done, and it would be very difficult if at all possible (and ethically questionable) to simulate the tiny excess of energy deposited in the fat storages during obesity development. Large-scale, long-term cohort studies covering a very broad range of energy intake and expenditure at baseline and a great diversity in subsequent weight changes have failed to show any relationship between these habits and weight changes [7]. Concomitant recording of food intake and physical activity alongside with the weight changes have suggested relationships between the habits and weight change [8], but this type of study will unavoidably mix any possible causal effect with the consequences of weight gain and obesity on these habits, even if multiple assessments are employed, where the tight association of weight loss and subsequent weight gain will confound the analyses.

The available evidence suggests that triglycerides, when stored as intracellular droplets in adipocytes and also in other cell types, are biologically inert [9]. The ability to store reserve energy as triglyceride for later use is widespread in nature and essential for survival, e.g. in migrating birds and hibernating animals. Evolution has provided most moving organisms with fat depots and well-functioning machinery to both store and release the energy from the stores when needed. I propose that the triglyceride storage is a healthy, natural response to a sensed possible lack of energy supplies in the future, also in human beings. If the body continues to sense the possible future lack of energy supplies, but it never happens, then obesity will develop and be maintained. This theory opens up for an avenue of novel research questions that may be crystallized in hypotheses empirically testable in existing or new data.

The questions may be divided in three series; one series about how and when the sensing of future lack of energy supplies occurs, the second series about how the signal of such future lack of energy translates to development of obesity, and the third about why and in whom the co-morbidities associated with obesity occurs. The latter series of questions were addressed in a previous editorial based on the idea that there are limits of expandability of the adipose tissue, that these limits exhibit considerable individual differences and that the metabolic alterations emerges when the triglyceride storage capacity in the adipose tissue is fully exploited, but the exposure to excess fatty acids continues $[9,10]$. This is presumed to induce a state of lipotoxicity, leading to cellular dysfunction, apoptosis, inflammation, insulin resistance and the metabolic alterations that eventually predisposes to diabetes, 
hypertension, cardiovascular diseases, various types of cancer and possibly several other co-morbidities.

Answers to the first series of questions about sensing the future lack of energy supplies implies a mechanism allowing prediction of the future lack of energy. Current shortage of food is a logical indicator of later shortage, and this is behind the American concept of food insecurity. A substantial fraction of the population in the USA, in spite of its wealth, suffers from food insecurity, and this is also a fraction with a very high prevalence of obesity [11]. In the above mentioned animal experiments, comparing groups in which food supply was reduced by $5 \%$ of the estimated needs with groups with normal supplies, the group subjected to reduced supplies developed greater fat stores [5]. The fact that the accumulation of energy also may go on in spite of plenty of energy in current environment without any indications of lack in the foreseeable future means that the prediction is not necessarily based on the current state of the energy supplies.

I propose that the sensing is based on the social conditions the individuals are currently living in. This is inspired by the overwhelming evidence for the very important role of social factors in obesity that has emerged since the first study was published in 1965 by Goldblatt, Moore and Stunkard [12], and by the evidence suggesting that social effects of obesity may in a vicious cycle add to continued development of obesity [13]. The proposition is based on the assumption that getting food always has been a social activity, where the individual has been dependent on others in the group they live in to get food. Thus, any social challenge, disturbance, disintegration or disruption would then imply insecurity in the future supply of food where food is not in abundance. Sensing of such social insecurity would be read by the body as the risk of possible future lack of energy, irrespective of the current and predicted availability of food.

Obviously, the sensing of the social insecurity needs to be translated to psychological processes with eventual biological consequences. These processes cannot be dependent on conscious cognitive processing of information about true lack of food, since they go on when there is no such current lack or a cognitive awareness of an expected future lack. On the other hand, there is ample evidence that obesity develops under conditions where social insecurity is prevalent [14-17]. The problems may be embedded in the psychosocial microenvironment, for example within a family between parents and children [14] or between other relatives, friends and peers. The insecurity may be associated with social position in the social classes or hierarchy of the society, whether living in upper-level fragile positions in developing societies or in lower levels with constraints and shortages in developed societies $[15,16]$. The challenges in the modern, dynamically developing and demanding society may leave a great segment of the population in insecurity. Even the political systems with different societal welfare support modalities, leaving a greater or smaller fraction of the population in living conditions with more or less social insecurity, may influence the development of obesity [17].

The answer to the question about when the sensing of insecurity that is subsequently translated to the increased tendency to development of obesity occurs should encompass the fact that the relation between social insecurity and occurrence of obesity is observed both at ages where the individual that senses the insecurity develops obesity and at ages, among the very young children, where the insecurity sensing is unlikely to occur. From an evolutionary perspective it makes sense to allow the sensing of insecurity to occur among parents who then through some mechanism transfer the strengthened ability to store reserve energy to their offspring. Findings of associations between social position and body weight in offspring not raised by the parents [18] suggest that such transfer mechanism might operate possibly through pleiotropic genetic effects, epigenetic modifications of the germ-line genomes before conception or through foetal programming. The finding of an 
increased risk of childhood obesity following bereavement before conception rather than during pregnancy [19] suggests epigenetic effects.

The answers to the second series of questions about how the psychological signal of social insecurity is translated to development of obesity may be separated into questions about how the development of the adipose tissue is regulated and questions about how the deposition of triglycerides in the adipose tissue is regulated. The transmission of the psychological signal may pass through a series of psycho-neurobiological mechanisms influencing both processes, but through different pathways. Although the adipocyte pool appears to be continuously renewed [20], the individually different upper limits of expandability of the fat stores indicate that the cellular renewal process is subject to a regulation that may depend on gender, age and circumstances. The deposition of triglycerides in the adipose tissue is likely to be regulated by the integrated central-peripheral neuroendocrinology systems [21] that are also involved in the regulation of food intake by appetite, nutrient metabolism and the processes in the adipocytes ending in their storage of more or less triglyceride [22]. A combination of number of fat cells and a maximum fat cell size is a likely determinant of the upper limit of triglyceride storage. There is clearly a disconnection between the adaptation of adipocyte development and the filling of the adipocyte with triglycerides in the response to the regulatory signals, which may also reflect the difference between developments of true adiposity and the weight gain observed at artificial overfeeding. Although multiple complex processes may be operating in this system, the claim of the present theory is that the overarching regulation of the amount of triglyceride stored in the body is determined by the signal of insecurity read as indication of a need of the energy in the future.

The recognition of the storage of triglyceride as an innocent, possibly beneficial process, which, however, has upper limits that should not be approached, is clearly calling for a paradigm shift in obesity research. This implies development of a novel theory that may inspire research possibly delivering novel knowledge, which through innovations may be translated to new modalities for coping with the obesity epidemic and its devastating consequences for the individual as well as for the societies. If the theory based on the insecurity signal is true, obvious targets for preventing and treating obesity may emerge.

\section{References}

1 Hall KD, Sacks G, Chandramohan D, Chow CC, Wang YC, Gortmaker SL, Swinburn BA: Quantification of the effect of energy imbalance on bodyweight. Lancet 2011;378:826-837.

2 Sørensen TI: Challenges in the study of causation of obesity. Proc Nutr Soc 2009;68:43-54.

3 McAllister EJ, Dhurandhar NV, Keith SW, Aronne LJ, Barger J, Baskin M, Benca RM, Biggio J, Boggiano MM, Eisenmann JC, Elobeid M, Fontaine KR, Gluckman P, Hanlon EC, Katzmarzyk P, Pietrobelli A, Redden DT, Ruden DM, Wang C, Waterland RA, Wright SM, Allison DB: Ten putative contributors to the obesity epidemic. Crit Rev Food Sci Nutr 2009;49:868-913.

4 Swinburn BA, Sacks G, Hall KD, McPherson K, Finegood DT, Moodie ML, Gortmaker SL: The global obesity pandemic: shaped by global drivers and local environments. Lancet 2011;378:804-814.

5 Li X, Cope MB, Johnson MS, Smith DL Jr, Nagy TR: Mild calorie restriction induces fat accumulation in female C57BL/6J mice. Obesity (Silver Spring) 2010;18:456-462.

6 Jeffery RW, Drewnowski A, Epstein LH, Stunkard AJ, Wilson GT, Wing RR, Hill DR: Long-term maintenance of weight loss: current status. Health Psychol 2000;19(1 suppl):5-16.

7 Summerbell CD, Douthwaite W, Whittaker V, Ells LJ, Hillier F, Smith S, Kelly S, Edmunds LD, Macdonald I: The association between diet and physical activity and subsequent excess weight gain and obesity assessed at 5 years of age or older: a systematic review of the epidemiological evidence. Int J Obes (Lond) 2009; 33(suppl 3):S1-92.

8 Mozaffarian D, Hao T, Rimm EB, Willett WC, Hu FB. Changes in diet and lifestyle and long-term weight gain in women and men. N Engl J Med 2011;364:2392-2404.

9 Sørensen TI, Virtue S, Vidal-Puig A: Obesity as a clinical and public health problem: is there a need for a new definition based on lipotoxicity effects? Biochim Biophys Acta 2010;1801:400-404. 
10 Sørensen TI: Obesity defined as excess storage of inert triglycerides - do we need a paradigm shift? Obes Facts 2011;4:91-94.

11 Larson NI, Story MT: Food insecurity and weight status among U.S. children and families: a review of the literature. Am J Prev Med 2011;40:166-173.

12 Goldblatt PB, Moore ME, Stunkard AJ: Social factors in obesity. JAMA 1965;192:1039-1044.

13 Stunkard AJ, Sørensen TI: Obesity and socioeconomic status - a complex relation. N Engl J Med 1993;329: 1036-1037.

14 Lissau I, Sørensen TI: Parental neglect during childhood and increased risk of obesity in young adulthood. Lancet 1994;343:324-327.

15 Due P, Damsgaard MT, Rasmussen M, Holstein BE, Wardle J, Merlo J, Currie C, Ahluwalia N, Sørensen TI, Lynch J: Socioeconomic position, macroeconomic environment and overweight among adolescents in 35 countries Int J Obes (Lond) 2009;33:1084-1093.

16 Senese LC, Almeida ND, Fath AK, Smith BT, Loucks EB: Associations between childhood socioeconomic position and adulthood obesity. Epidemiol Rev 2009;31:21-51.

17 Offer A, Pechey R, Ulijaszek S: Obesity under affluence varies by welfare regimes: the effect of fast food, insecurity, and inequality. Econ Hum Biol 2010;8:297-308.

18 Fontaine KR, Robertson HT, Holst C, Desmond R, Stunkard AJ, Sørensen TI, Allison DB: Is socioeconomic status of the rearing environment causally related to obesity in the offspring? PLoS One 2011;6:e27692.

19 Li J, Olsen J, Vestergaard M, Obel C, Baker JL, Sørensen TI: Prenatal stress exposure related to maternal bereavement and risk of childhood overweight. PLoS One 2010;5:e11896.

20 Spalding KL, Arner E, Westermark PO, Bernard S, Buchholz BA, Bergmann O, Blomqvist L, Hoffstedt J, Näslund E, Britton T, Concha H, Hassan M, Rydén M, Frisén J, Arner P: Dynamics of fat cell turnover in humans. Nature 2008 5;453:783-787.

21 O'Rahilly S, Farooqi IS: Human obesity: a heritable neurobehavioral disorder that is highly sensitive to environmental conditions. Diabetes 2008;57:2905-2910.

22 Arner P, Bernard S, Salehpour M, Possnert G, Liebl J, Steier P, Buchholz BA, Eriksson M, Arner E, Hauner H, Skurk T, Rydén M, Frayn KN, Spalding KL: Dynamics of human adipose lipid turnover in health and metabolic disease. Nature 2011;478:110-113. 